\section{Elastic or inelastic compression in patients with leg ulcer and restricted mobility?}

\section{Giovanni Mosti}

Angiology Department, Clinica MD

Barbantini, Lucca, Italy

\section{Abstract}

In patients with leg ulcer and restricted mobility, compression with elastic material is often preferred based on the concept that it is more effective as it exerts a sustained higher resting pressure while inelastic material is believed to exert a very low resting pressure and to work only during movement. The aim of this study is to demonstrate that elastic and inelastic material can exert similar pressure at rest and that inelastic material can produce a much higher pressure during sitting and light exercise in ulcer patients with restricted mobility. In 30 patients (12 men, 18 women mean age $76.3 \pm 9.1$ years, range $63-80$ ) with leg ulcers and severely reduced mobility we applied consecutively elastic and inelastic bandages with the same resting pressure of 40 $\mathrm{mmHg}$. Pressure changes were measured while the patient was sitting and standing and during active and passive muscle contractions. The pressure differences between standing and supine and sitting and supine position were calculated as well as between muscle systole and diastole during active and passive contractions. Starting with the same resting pressure inelastic bandages produce significantly higher pressure peaks in the sitting and standing position and during the muscular systole both during active and passive exercise compared to elastic bandages $(\mathrm{P}<0.001)$. The results show that inelastic bandages, applied with the same pressure as elastic bandages at rest, will exert much higher pressures even during minimal or passively induced muscle contractions. The concept that elastic compression should be used in patients with reduced mobility needs to be reconsidered.

\section{Introduction}

Immobility or severely impaired mobility represent an indication for compression therapy in order to prevent venous thromboembolism ${ }^{1-4}$ and to reduce edema that will devel${ } \mathrm{p}^{5-11}$ when the patient spends his life mainly in a sitting position or is unable to move cor- rectly for any other reason. These conditions are frequently considered as an indication for elastic compression ${ }^{12-13}$ based on the concept that it can exert a high, sustained, resting pressure in contrast to inelastic compression which would produce a low resting pressure and would be effective only in the standing position and, especially, during muscle contraction.

The aim of this study is to show that, in patients with leg ulcers who are immobile or with restricted mobility, inelastic bandages can exert a pressure at least as high as elastic material at rest but much higher even during minimal movements, and, as a consequence, much more effective to counteract the venous hemodynamic impairment.

\section{Materials and Methods}

Thirty patients (12 men, 18 women mean age $70.3 \pm 10.1$ years, range $59-80$ ) with leg venous ulcers and severely impaired mobility who spent most of the day either sitting in an armchair with limited ambulation or in bed were enrolled. All of them were fully informed and gave their written consent to participate in the study.

Ethical committee approval is not requested in Italy for studies comparing CE (European Community) marked products and not requiring randomization in different groups (they are considered as observational studies).

Inclusion criteria: patients of both sexes, age from 20 to 80 years, suffering from venous leg ulcers and with restricted mobility [patients who, for different health problems (orthopedic, cardio-respiratory, overweight) spend their life lying in bed or sitting in an armchair but able to move for their simple needs]. Exclusion criteria: patients with arterial impairment and an ankle-brachial pressure index $<0.8$ or with complete block of ankle, knee, hip joints were excluded from the study.

In all patients the same experienced bandager successively applied an elastic and inelastic bandage from the base of the toes to the popliteal fossa in the supine position, in a randomized sequence. The time interval between the two applications was 30 min during which the patient stayed resting in bed. As elastic bandage we used Dauerbinde $K{ }^{\circledR}$ (Lohmann \& Rauscher, Rengsdorf, Germany) stretched by $50-60 \%$ and overlapped by $50-60 \%$; the inelastic bandage was made up of cotton padding layer and a cohesive inelastic bandage (Cellona ${ }^{\circledR}$, Mollelast Haft ${ }^{\circledR}$; Lohmann \& Raucher) applied with full stretch and superimposed by $50 \%$.
Correspondence: Giovanni Mosti, Angiology Department, Clinica MD Barbantini, via del Calcio, 55100 Lucca, Italy.

E-mail: jmosti@tin.it

Key words: elastic compression, inelastic compression, leg ulcers, reduced mobility, immobility.

Received for publication: 30 July 2013.

Revision received: 1 October 2013.

Accepted for publication: 17 October 2013.

This work is licensed under a Creative Commons Attribution 3.0 License (by-nc 3.0).

(C) Copyright G. Mosti, 2013

Licensee PAGEPress, Italy

Veins and Lymphatics 2013; 2:e20

doi:10.4081/vl.2013.e20

In the lying position the bandager adjusted the pressure of each bandage to $40 \mathrm{mmHg}$ recorded by a validated ${ }^{14,15}$ pneumatic device with an air filled probe (Picopress ${ }^{\circledR}$ Microlab, Padua, Italy). The probe was placed at point B1 on the medial aspect of the calf where the tendinous part of the gastrocnemius turns in muscular part according to the recommendations of a Consensus document on sub-bandage pressure measurements in vivo. ${ }^{16}$

The patients were then asked to do maximal dorsiflexions end extension of the foot which were followed by maximal passive dorsiflexions and extension carried out by a physiotherapist. Finally patients were asked to move the toes actively as much as possible. The patients were then moved from the bed to the armchair where series of active and passive foot dorsiflexions (therapist-assisted) were carried out again. After that the patients were asked to stand, and to walk briefly with assistance if needed.

The exerted pressure was continuously measured in the supine, sitting and standing position and during active and passive ankle and toe movements. The following pressure differences were calculated: sitting minus supine position, standing minus supine position, the active systolic-diastolic difference and passive systolic-diastolic difference, the toe systolic-diastolic difference and the walking systolic-diastolic difference.

\section{Statistical analysis}

The results underwent statistical analysis using Student's $t$-test for paired data to compare the different maneuvers under the same bandage and the Student's $t$-test to compare elastic $v s$ inelastic bandages. Differences with $\mathrm{P}<0.05$ were considered statistically significant. The graphs were created with Graph Pad, version 5 (Graph Pad, San Diego, CA, USA). 


\section{Results}

The resting pressure increases significantly both with elastic and inelastic material during active and passive dorsiflexion, both in supine and sitting position, with the very small toe movements, in the sitting and standing position and during walking. The pressure increase produced by the inelastic material is significantly higher when compared with elastic $(\mathrm{P}<0.001)$ (Figures 1 and 2$)$.

As a consequence all the pressure differences (between sitting and supine position, standing and supine position, systolic and diastolic pressure during active and passive movements of ankle and toes and during walking) were significantly higher with inelastic compared with elastic material $(\mathrm{P}<0.001)$ (Figure 3) as can be seen in the pressure recordings (Figures 4 and 5).

\section{Discussion}

The pressure of a bandage does not depend on the elastic property of the material used ${ }^{17}$ but on the strength exerted by the bandager during wrapping. In this study elastic and inelastic bandages have been applied with exactly the same initial resting pressure in the lying position. By standing up and by different active or passive leg movements the pressure increase was always significantly higher with inelastic than with elastic material.

This finding is in disagreement with the concept that inelastic bandages produce a low resting pressure and achieve effective pressures only during movement. This is the reason why many clinicians believe that patients who are unable to move should better be treated by elastic material.

Elastic would be an active compression in the resting position while inelastic would be a passive or restraining compression, that produces low or no resting pressure, and would only be effective during muscular contraction.

It is also thought that since a patient with restricted mobility has little or no muscular activity this passive inelastic material would not be suitable to develop enough compression pressure.

Several experimental studies have clearly shown that inelastic compression can exert a significantly higher pressure compared with elastic both in supine and standing position and during work. ${ }^{18-20}$

By a general physics definition, elastic material tends to return to its original length once stretched; therefore it will not be tolerated if highly stretched to exert high pressure

(which could be termed the squeezing effect). Inelastic material doesn't have any elastic return property and can exert a high resting pressure without causing any pain.

This is the rationale for recommending the application of inelastic material with full stretch while elastic material should be applied with a stretch of $50-60 \%$ in order not to be painful.

A

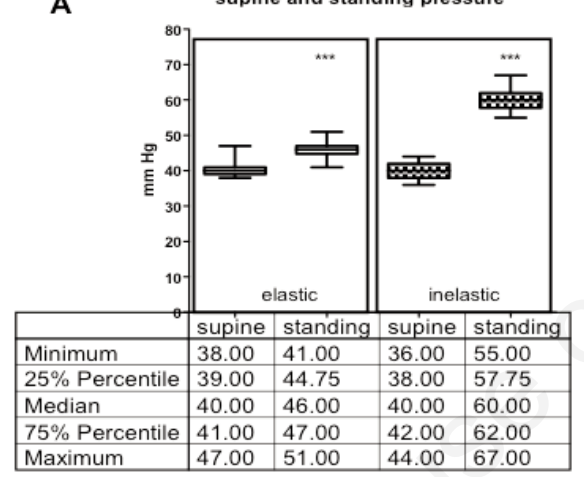

The resulting resting pressure of an inelastic bandage applied under full stretch will be higher than that of an elastic bandage and will be in the range indicated in a recent consensus document as strong $(40-60 \mathrm{~mm} \mathrm{Hg})$ or very strong ( $>60 \mathrm{mmHg}$ ) while the pressure exerted by an elastic bandage properly applies should not exceed $40-45 \mathrm{mmHg}$ (mediumstrong $)^{21}$ in order to be well tolerated. Since the

Figure 1. Pressure difference between elastic and inelastic material moving from supine to standing position (A), and from supine to sitting position (B). The pressure in the standing and in the sitting position is significantly higher $(\mathrm{P}<0.001)$ with inelastic material compared with elastic. ${ }^{* * *} \mathrm{P}<0.001 ;$ n.s., not significant.

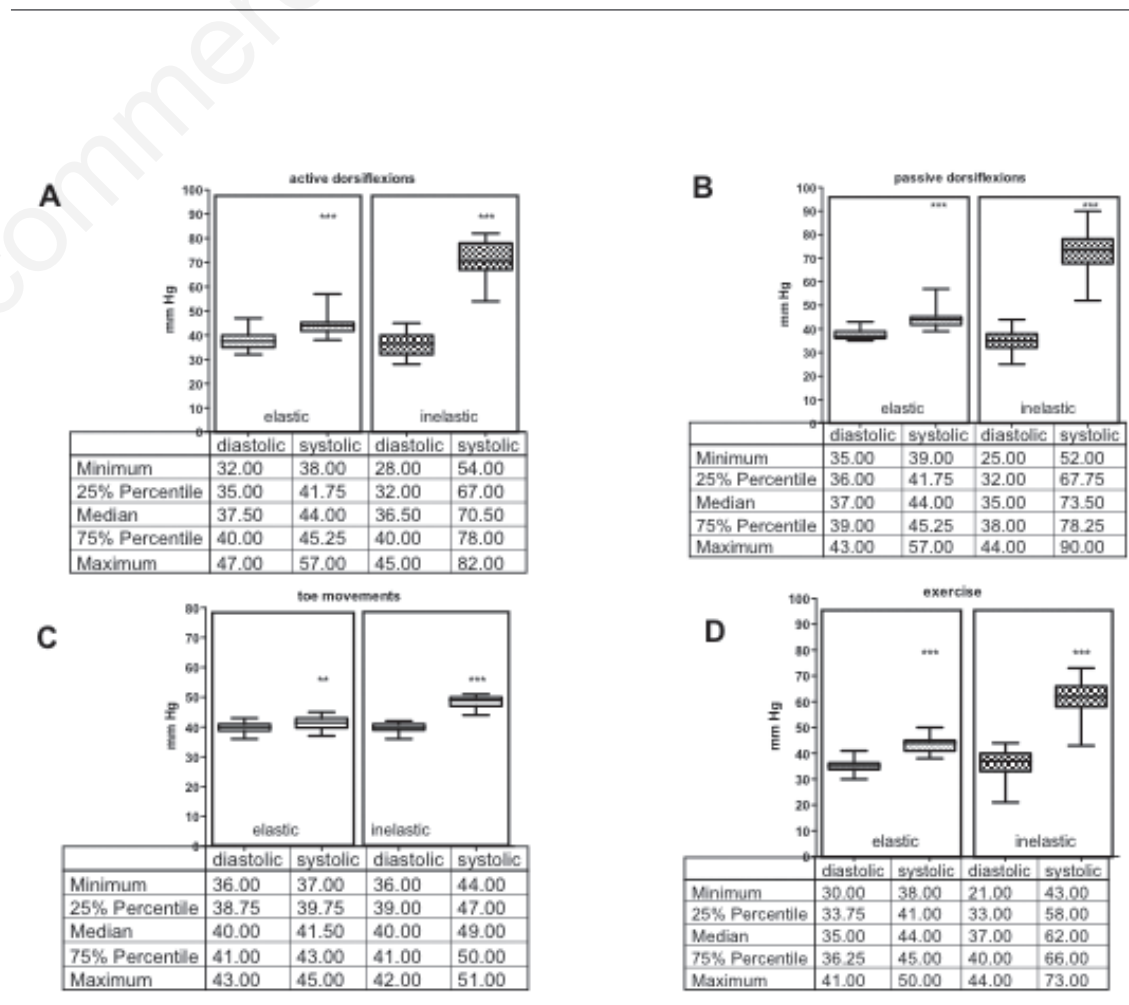

Figure 2. Pressure difference between elastic and inelastic material in muscular diastole and systole during active dorsiflexion (A), passive dorsiflexions (B), toe movements (C) and exercise (D). With inelastic material the pressure peaks are always significantly higher $(\mathbf{P}<0.001)$. ${ }^{* *} \mathbf{P}<0.01 ;{ }^{* * *} \mathbf{P}<0.001$. 
patients in this study spend most of the time in bed or in an armchair we intentionally did not use very strong pressure but choose to start with a resting pressure of $40 \mathrm{mmHg}$ that is able to narrow/occlude the vein both in the supine and sitting position. ${ }^{22}$

According to their elastic properties, elastic bandages give way to the muscle volume increase during contraction while inelastic material tends to form a stiff shell around the leg and does not give way. It is the leg which gives way with active or passive ankle-or toe movement.

Our results show that just with small muscular activity (foot dorsiflections, toes movements) inelastic material produces significantly higher pressure peaks than elastic material (Figures 3-5).

It could be demonstrated that higher sitting and standing compression pressure is positively correlated with a reduction of venous reflux even when the pressure at application of the different materials is the same. ${ }^{23,24}$ The high pressure amplitudes during active or passive movements correlate with a higher increase of venous pumping function. ${ }^{25}$

Measuring the ejection fraction of the calf pump it could be demonstrated that inelastic bandages revealed a significantly higher increase of venous pumping function compared with elastic bandages applied with the same resting pressure. This effect has been proved both in normal subjects ${ }^{26}$ and patients with venous insufficiency ${ }^{25}$ and was more pronounced in higher $60 \mathrm{mmHg}$ than in lower pressure ranges (20 and $40 \mathrm{mmHg}$ ). ${ }^{27}$

Even small and passive foot dorsiflexions or toe movements are able to produce amazing pressure amplitudes with inelastic compression (Figure 5). Such exercises can be carried out also passively by healthcare professionals or even trained relatives.

One disadvantage of inelastic compression is its rapid pressure loss. In a previous study we were able to show that, in spite of a consistent pressure loss, the inelastic bandage continues to be very effective in improving the calf muscle pump function even after a week, maintaining a significantly higher efficacy compared to elastic compression with a negligible pressure loss. ${ }^{28}$ The pressure loss can mainly be explained by edema reduction and material fatigue and makes the bandage more comfortable.

A weakness of our study is that only pressure values are reported. Comparing different compression materials functional parameters like ejection fraction or venous reflux would have been interesting outcome parameters but cannot reliably measured in our immobile population. Nevertheless the positive correlation between standing pressure or massage effect and venous reflux and ejection fraction has been widely proved. ${ }^{23-28}$
It can be reasonably assumed that it exists also in patients with restricted mobility provided they have some opportunities to move actively or even passively both in the bed and in the armchair.

\section{Conclusions}

The recommendation to use only elastic compression in immobile patients must be reconsidered.
A skilled bandager will apply inelastic compression at least with the same pressure exerted by the elastic bandage. Inelastic bandages produce higher pressure peaks than elastic material even during simple active or passive movements being able to increase the venous pump.

It may be assumed that the stronger massaging effect produced by inelastic material may have positive effects not only on venous hemodynamics but also on the microcirculation and on lymph-drainage.

If this positive effects on venous hemody-

\section{pressure differences with different exercise or body positions}

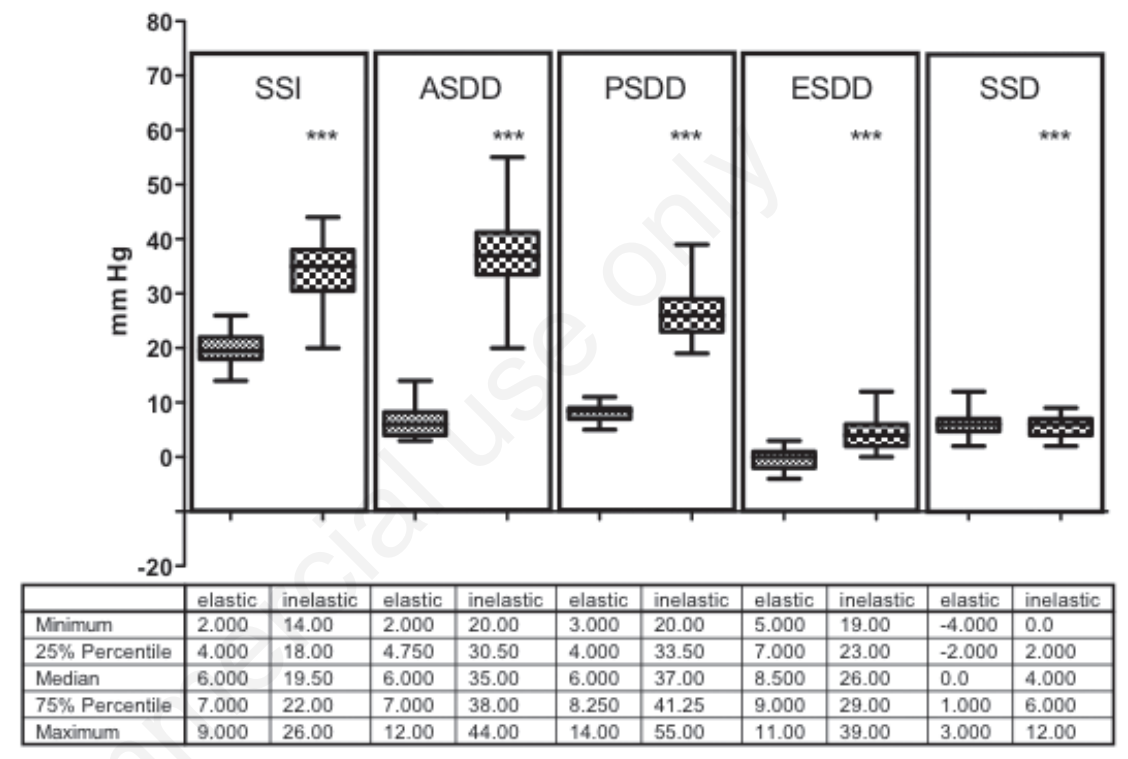

Figure 3. Pressure difference with different exercise or body position. ${ }^{* * *} \mathrm{P}<0.001$. SSI, standing minus supine position; ASDD, active systolic-diastolic difference; PSDD, passive systolic-diastolic difference; SSD, sitting minus supine position.

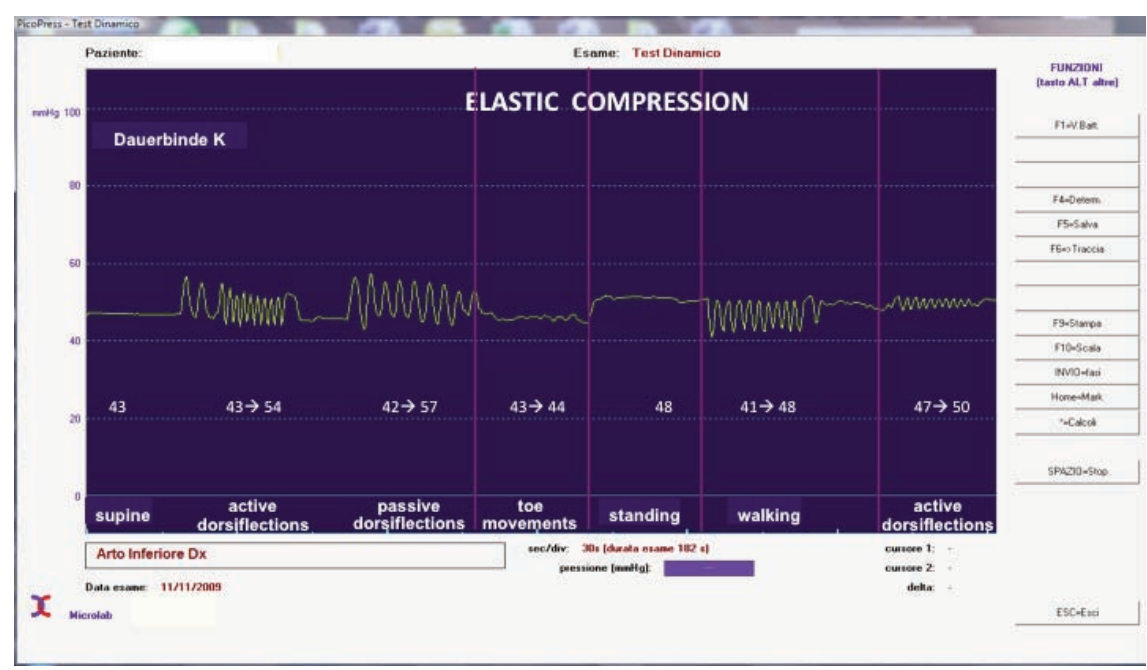

Figure 4. Pressure recordings with elastic compression: pressure peaks during active and passive dorsiflexions, toe movements, standing and walking are low. 


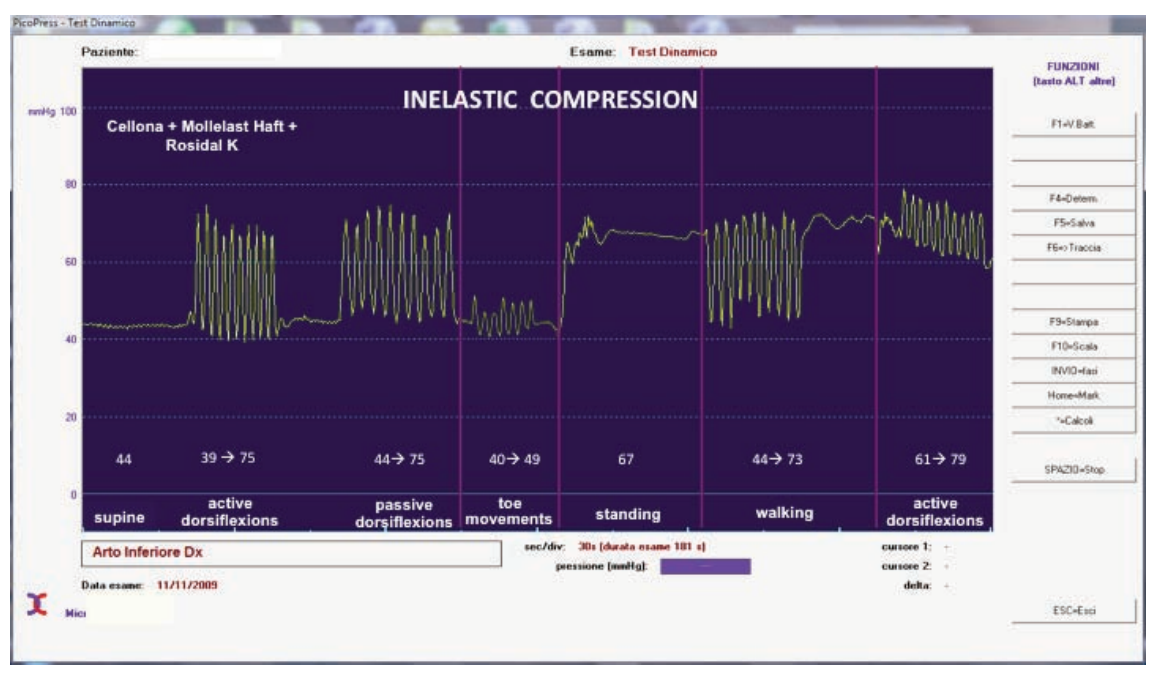

Figure 5. Pressure recordings with inelastic compression: pressure peaks during active and passive dorsiflexions, toe movements, standing and walking are very high and much higher compared with elastic compression starting from the same resting pressure.

namic reflect in a better outcome of leg ulcers in this group of patients is not an aim of our study and should be proved by future trials.

\section{References}

1. Amaragiri SV, Lees TA. Elastic compression stockings for prevention of deep vein thrombosis. Cochrane Database Syst Rev 2000;(3):CD001484.

2. Nicolaides AN, Fareed J, Kakkar AK, et al. Prevention and treatment of venous thromboembolism, International Consensus Statement (Guidelines according to scientific evidence). Int Angiol 2006;25:101-61.

3. Roderick P, Ferris G, Wilson K, et al. Towards evidence-based guidelines for the prevention of venous thromboembolism: systematic reviews of mechanical methods, oral anticoagulation, dextran and regional anesthesia as thromboprophylaxis. Health Technol Assess 2005;9:1-78.

4. Handoll HH, Farrar MJ, McBirnie J, et al. Heparin, low molecular weight heparin and physical methods for preventing deep vein thrombosis and pulmonary embolism following surgery for hip fractures. Cochrane Database Syst Rev 2000;27: CD000305.

5. Jonker MJ, deBoer EM, Adèr HJ, Bezemer PD. The oedema-protective effect of Lycra support stockings. Dermatology 2001;203:294-8.
6. Partsch H, Winiger J, Lun B. Compression stockings reduce occupational swelling. $\mathrm{J}$ Derm Surg 2004;30:737-43.

7. Clarke M, Hopewell S, Juszczak E, et al. Compression stockings for preventing deep vein thrombosis in airline passengers. Cochrane Database Syst Rev 2006; (2):CD004002.

8. Gniadecka M. Dermal oedema in lipodermatosclerosis: distribution, effects of posture and compressive therapy evaluated by high frequency ultrasonography. Acta Derm Venereol 1995;75:120-4.

9. Krijnen RM, de Boer EM, Ader HJ, et al. Compression stockings and rubber floor mats: do they benefit workers with chronic venous insufficiency and a standing profession $\mathrm{J}$ Occup Environ Med 1997;39:889-94.

10. Diehm C, Trampisch HJ, Lange S, Schmidt C. Comparison of leg compression stocking and oral horse-chestnut seed extract therapy in patients with chronic venous insufficiency. Lancet 1996,347:292-4.

11. Van Geest AJ, Veraart JC, Nelemans P, Neumann HA. The effect of medical elastic compression stockings with different slope values on edema. Measurements underneath three different types of stockings. Dermatol Surg 2000;26:244-7.

12. WUWHS. Principles of best practice: compression in venous leg ulcers. A consensus document. London: MEP Ltd, 2008.

13. EWMA. Understanding compression therapy. EWMA Position Document. London: MEP Ltd, 2003. pp 13-14.

14. Partsch H, Mosti G. Comparison of three portable instruments to measure compression pressure. Int Angiol. 2010;29:426-30.

15. Mosti G, Rossari S. L'importanza della misurazione della pressione sottobendaggio e presentazione di un nuovo strumento di misura. Acta Vulnol 2008;6:31-6.

16. Partsch H, Clark M, Bassez S, et al. Measurement of lower leg compression in vivo: recommendations for the performance of measurements of interface pressure and stiffness. A consensus statement. Dermatol Surg 2006;32:229-38.

17. British Standard. The elastic properties of flat, non-adhesive, extensible fabric bandages. BS 705 1995. London: BSI-British Standards Institution; 1995.

18. Mosti G, Mattaliano V. Simultaneous changes of leg circumference and interface pressure under different compression bandages. EJVES 2007;33:476-82.

19. Partsch H. The static stiffness index: a simple method to assess the elastic property of compression material in vivo. Derm Surg 2005;31:625-30.

20. Partsch $\mathrm{H}$. The use of pressure change on standing as a surrogate measure of the stiffness of a compression bandage. Eur J Vasc Endovasc Surg 2005;30:415-21.

21. Partsch H, Clark M, Mosti G, et al. Classification of compression bandages: practical aspects. Dermatol Surg 2008; 34:600-9.

22. Partsch B, Partsch H. Calf compression pressure required to achieve venous closure from supine to standing position. $\mathrm{J}$ Vasc Surg 2005;42:734-8.

23. Mosti G, Partsch H. Duplex scanning to evaluate the effect of compression on venous reflux. Int Angiol 2010;29:416-20.

24. Partsch H, Menzinger G, Mostbeck A. Inelastic leg compression is more effective to reduce deep venous refluxes than elastic bandages. Dermatol Surg 1999;25:695700.

25. Mosti G, Mattaliano V, Partsch H. Inelastic compression increases venous ejection fraction more than elastic bandages in patients with superficial venous reflux. Phlebology 2008;23:287-94.

26. Poelkens F, Thijssen DHJ, Kersten B, et al. Counteracting venous stasis during acute lower leg immobilization. Acta Physiol 2006;186:111-8.

27. Mosti G, Partsch H. Is low compression pressure able to improve venous pumping function in patients with venous insufficiency? Phlebology 2010;25:145-50.

28. Mosti G, Partsch H. Inelastic bandages maintain their hemodynamic effectiveness over time despite significant pressure loss. J Vasc Surg 2010;52:925-31. 